\title{
Consequences of customer engagement behavior: when negative Facebook posts have positive effects
}

\author{
Sofie Bitter ${ }^{1}$ Sonja Grabner-Kräuter ${ }^{1}$
}

Received: 23 March 2015 / Accepted: 11 March 2016/Published online: 1 April 2016

(C) The Author(s) 2016. This article is published with open access at Springerlink.com

\begin{abstract}
Sharing product information has become an integral part of today's online social networking world. This research study addresses the effects of customer engagement behavior in online social networks on other consumers in order to understand how online social connections impact decision making. We investigate how different variations of a brand-related Facebook post trigger different response reactions. In particular, we analyze under which conditions negative posts can have positive consequences. The results of two online experiments set in a restaurant context suggest a difference when the user knows the restaurant brand. For users who are familiar with the restaurant brand, a positive effect of negative information posted by distant acquaintances is found with regard to the visiting intention of the user. The results of both experiments demonstrate that information posted by a close friend is perceived to be more diagnostic. For users not familiar with the restaurant brand, negative posts from strong ties induce the highest diagnosticity levels.
\end{abstract}

Keywords Social networking sites $\cdot$ Facebook $\cdot$ Customer engagement behavior $\cdot$ Valence $\cdot$ Tie strength $\cdot$ Diagnosticity

JEL Classification M31 Marketing

Responsible Editors: Ulrike Baumöl and Linda Hollebeek

Sofie Bitter and Sonja Grabner-Kräuter contributed equally to this work.

Sofie Bitter

sofie.bitter@aau.at; sonja.grabner@aau.at

1 Universitätsstrasse 65-67, 9020 Klagenfurt, Austria

\section{Introduction}

Online social networking is more popular than ever before and increasingly impacts consumer purchase decisions. Resulting in a facilitated access to other consumers' feedback, the proliferation of social networking sites offers fundamentally new ways of engagement and interaction among existing as well as potential consumers and brands (e.g., Hess et al. 2011; Kabadayi and Price 2014). Nowadays, it is impossible to imagine online life without engaged and active users. Following this, the concept of customer engagement behavior, defined by van Doorn et al. as "customer's behavioral manifestations that have a brand or firm focus, beyond purchase, resulting from motivational drivers" (2010, p. 254), has become an issue that is currently the focus of much attention and activity.

For both marketers and academics, it is of interest to understand the consequences of customer engagement in online social networks (OSNs). Nonetheless, there is a paucity of scholarly research related to a coherent understanding of how social connections in OSNs impact decision making (Takac et al. 2011). In other words, little is known about "the relationship between customer behavioral engagement and other proximal constructs" (Gummerus et al. 2012, p. 858); for example, to what extent the formation of consumer attitudes is driven by specific consumer "engagement" cognitions, emotions and behaviors, or what effects on consumer purchase intentions can be expected (Hollebeek and Chen 2014). This illustrates the need to examine the outcomes that result from customers' brandrelated interactions in OSNs. Besides, the majority of pioneering research has tended to focus on positively valenced customer engagement and thus has largely overlooked potential negatively valenced manifestations of this emerging concept and their implications for (other) consumers and business firms (Hollebeek and Chen 2014). 
This study seeks to address this void by examining potential effects of both positively and negatively valenced behavioral manifestations of customer engagement on Facebook. The interest in Facebook is motivated by the undeniable popularity of the platform - Facebook is the largest and most widely used social networking site in the world, connecting over 1.39 billion monthly active users (Facebook 2015) and hosting over 50 million brand pages (Facebook 2013). Naturally, one could argue that positive brand-related Facebook posts trigger positive impressions and negative posts result in negative impressions. Contrary to this intuitive expectation and building on previous research (e.g., Berger et al. 2010; Ein-Gar et al. 2012; Hamilton et al. 2014), we suggest that, under certain conditions, a small piece of negative information, such as a negative Facebook comment, might affect the product evaluation in a positive way.

Previous studies have shown that the consequences of product-related information and recommendations as a behavioral expression of customer engagement can differ, depending on whether the information source is a close friend (i.e. a strong tie) or a distant acquaintance (i.e. a weak tie) (e.g., Bansal and Voyer 2000; Sen and Lerman 2007; Steffes and Burgee 2009; Wang and Chang 2013). Drawing on these findings, we investigate the moderating role of tie strength on the impact of comment valence on purchase decision making. An experimental design in a restaurant brand context was set up in order to demonstrate the differential impact of different variations of a brand-related Facebook comment as particular behavioral manifestation of customer engagement. Our investigation was guided by the following research questions:

RQ 1: Are conditions observable that induce positive effects from negatively valenced customer engagement behavior on Facebook?

RQ 2: If so, under which conditions can negatively valenced customer engagement behavior on Facebook have positive consequences for brand evaluation and information diagnosticity?

RQ 3: What influence on brand evaluation and information diagnosticity can be expected from positively vs. negatively valenced customer engagement behavior that is performed by either a close friend or a distant acquaintance?

To address these research questions, we analyze how negatively valenced as distinct from positively valenced brandrelated information from a close as distinct from a distant Facebook friend influences the consumer's visiting intention and the Facebook post's perceived diagnosticity. Referring to the "blemishing effect" described by (Ein-Gar et al. 2012) we first examine if a negatively valenced brand-related Facebook comment from a distant friend can induce a positive effect on brand evaluation. We expect a positive effect of such a minor piece of negative information on visiting intentions only in a situation when users are familiar with the restaurant brand and have a positive attitude towards it, since a positive attitude towards the brand is a precondition for the blemishing effect to occur. We also examine the impact of the different variations of the Facebook post on perceived diagnosticity, which can be described as the degree to which the consumer believes the information they receive is useful in evaluating the brand's attributes (see e.g. Kempf and Smith 1998). Due to the negativity bias in information diagnosticity (e.g., Herr et al. 1991; Mizerski 1982), negatively valenced posts can be expected to be perceived as more diagnostic and useful for the evaluation of the restaurant brand than positively valenced comments. In a situation when users are unfamiliar with the restaurant brand, the expected "positive effect" of a negative Facebook comment should still manifest itself in its higher perceived diagnosticity, as suggested by the negativity bias. Additionally, the effect should be stronger for negative comments from close friends. In the remainder of this paper, we briefly review the literature and suggest a conceptual framework for hypothesis development that links Service-Dominant (S-D) logic with the concept of tie strength from social network theory. Next, we report on two experimental studies analyzing Facebook users' reactions to manipulated Facebook posts to test our hypotheses. The paper closes with theoretical and managerial implications, limitations and future research directions.

\section{Literature review and hypotheses development}

\section{Customer engagement behavior and its consequences}

During the past decade, the concept of customer engagement has received increasing attention from both marketing practitioners and researchers. The Marketing Science Institute has identified "customer engagement" as a key research area contributing to an improved understanding of consumer behavior in complex, interactive and/or co-creative environments (Marketing Science Institute 2010). Meanwhile, the theoretical meaning and foundations of the customer engagement concept have been established in the marketing and service literature (Brodie et al. 2011; Hollebeek and Chen 2014; Vivek et al. 2012). However, to date, there is still a relative deficit in empirical studies on customer engagement in general and even fewer exist on customer engagement in social media (e.g., Bitter et al. 2014; Gummerus et al. 2012; Hollebeek and Chen 2014).

Origins of engagement-based concepts such as "brand engagement" or "customer engagement" can be traced to various academic disciplines including psychology, sociology and organizational behavior (Brodie et al. 2011; Vivek et al. 2012). Brodie et al. (2011) provide a comprehensive conceptual 
analysis of customer engagement in the marketing and service literature and suggest that its conceptual roots can best be explained by drawing on theoretical approaches that address interactive experience and value co-creation within marketing relationships. From this perspective, consumers are not viewed primarily as passive recipients of marketing cues but rather as proactive participants in interactive, value-generating co-creation processes (Hollebeek 2013; Sawhney et al. 2005; Vargo and Lusch 2004, 2008). Accordingly, the theoretical foundations of the customer engagement concept are established in the expanded domain of relationship marketing, and the S-D logic (Brodie et al. 2011; Vivek et al. 2012). Brodie et al. (2011) point out that specific fundamental propositions underlying the S-D logic are of particular relevance for substantiating the customer engagement concept. This reflects customers' interactive, co-creative activities and experiences with other stakeholders in focal, networked service relationships (for a detailed explanation see Brodie et al. 2011).

Several definitions of customer engagement have been proposed in the marketing and service literature (see the overview e.g. in Hollebeek 2013). The majority of definitions adopt a multidimensional view of engagement, whereby threedimensional (i.e., cognitive, emotional and behavioral) customer engagement concepts have been suggested in the literature most often (Brodie et al. 2011). Obviously, the concept of customer engagement behavior (CEB) refers to the behavioral dimension of customer engagement. The specific expressions of the cognitive, emotional and behavioral dimension may vary across different engagement-based concepts and contexts (Hollebeek 2013; Vivek et al. 2012). With the advent of Web 2.0 technologies and applications, particularly the number of behavioral engagement options for customers has grown dramatically (van Doorn et al. 2010), requiring specific research efforts. Hence, in this paper, we focus on behavioral manifestations of customer engagement on social networking sites.

From a managerial perspective, "[m]any CEBs such as referral behaviors, [word-of-mouth] WOM behaviors, and actions aimed at generating and disseminating information (e.g., blogging) should affect purchase behavior of focal as well as other customers and consequently customer equity" (van Doorn et al. 2010, p. 259). Previous empirical studies on the consequences of customer engagement found that, to some extent, growing customer engagement generates greater customer value increases for hedonic than for utilitarian brands (Hollebeek 2012). Wei et al. (2013) concentrate on one particular type of customer engagement behavior, namely on usergenerated hotel reviews and analyze potential customers' perceptions of CEB and hotels' management responses to CEB. Gummerus et al. (2012) examine the effect of customer engagement behaviors on perceived relationship benefits and relationship outcomes. Jahn and Kunz (2012) focus on Facebook fan page participation and its impact on the customer brand relationship. A study by Pan and Chiou (2011) tests the effects of strong vs. weak social relationships and positive vs. negative messages on perceived trust of online information in a discussion forum. However, empirical studies on the consequences of brand-related comments by Facebook users as a specific manifestation of CEB remain scarce.

As mentioned above, CEB on social networking sites can find its expression through positive (e.g., posting a liking comment on a brand community site) or negative actions (e.g., posting a negative brand message on Facebook) (e.g., Brodie et al. 2011; Hollebeek and Chen 2014; van Doorn et al. 2010). In any case, the importance of negative behavior should not be ignored. Previous research in an electronic word-of-mouth (for a conceptual definition of eWOM and a systematic review of eWOM research see e.g. Cheung and Thadani 2012) and online review context shows that negative comments have stronger effects on purchase decisions, in contrast to positive electronic word-of-mouth (Chang and $\mathrm{Wu}$ 2014; Lee et al. 2008). It is suggested "that unfavorable information is somehow more shocking or surprising, and therefore has more influence on forming evaluations". (Mizerski 1982, p. 302). However, as Hollebeek and Chen (2014) point out as a result of a comprehensive literature review, the majority of research has focused on positively valenced expressions of customer and/or brand engagement and thus has neglected negatively valenced manifestations of customer engagement. Therefore, this research study considers both variations of message valence, positive and negative, to investigate how Facebook users' brand-related comments affect visiting intentions with regard to a restaurant.

Intuitively, one would assume that positive brand-related comments lead to higher visiting intentions and negative brand-related comments lead to lower visiting intentions. In contrast to this intuition, research has shown that weak negative information might sometimes enhance the evaluation of an object (Ein-Gar et al. 2012). In their seminal study Lord et al. (1979) found that when people already have a positive attitude toward an object or issue and receive contradictory arguments this can polarize or intensify their positive attitude, because people discount the contradictory information and reinforce the initial information that lead to the original attitude. Another study on the positive effects of negative publicity (Berger et al. 2010) indicates that not all negative word-of-mouth should be quieted, because in some instances it can actually have positive effects. In a series of elaborate studies, Ein-Gar et al. (2012) found that in situations of low processing effort a small dose of negative information that follows positive information appears to enhance consumers' overall evaluations of the product. They refer to this as the positive effect of negative information weak negative information that merely blemishes a target can actually enhance its impression under specific conditions (blemishing effect) (Ein-Gar et al. 2012). 
We suggest that a product- or brand-related comment in an online social network might sometimes represent such a minor piece of conflicting information, which could accentuate rather than attenuate an initial positive impression. In a situation when processing effort is low, a negative Facebook post could prompt a reevaluation of the product or brand and trigger bolstering processes (Ein-Gar et al. 2012) that lead to a higher purchase (or visiting) intention than a positive post. However, we assume that the potentially positive effect of negative brand-related information on a social networking site such as Facebook depends on whether or not the user knows the product in question and on her/his prior (positive) brand attitude. Beyond that, we suggest that this effect might interact with context factors that can have an influence on the information processing effort of the user. Specifically, we expect a moderating effect of the type of Facebook friend who posts the comment.

\section{The role of tie strength}

Linking S-D logic with concepts from social network theory offers a complementary understanding to better explain processes of resource access and exchange (Laud et al. 2015). The central premise underlying social network theory is that actors such as business firms and customers are embedded in networks of interconnected social relationships (i.e. "ties") that provide opportunities for and constraints on behavior (Brass et al. 2004; Burt 1997).

From a social network perspective, OSNs can be viewed as a mix of social connections or ties, through which network members obtain access to the resources of other actors (Tsai and Ghoshal 1998). It is indeed the sociality factor of OSNs, which motivates users to adopt them, ultimately impacting users' social capital (Chang and Zhu 2012; Grabner-Kräuter and Bitter 2015). In online social networks, users are usually connected by both strong and weak ties (DeAndrea et al. 2012; Wang and Chang 2013). Granovetter (1973, p. 1361) refers to tie strength as the "combination of the amount of time, the emotional intensity, the intimacy (mutual confiding), and the reciprocal services which characterize the tie". As weak ties usually connect individuals from otherwise diverse groups, they are more likely to provide access to more heterogeneous, novel and diverse information compared to strong ties (Levin et al. 2002).

In an OSN context, weak ties are considered in a relational way, i.e., they connect acquaintances who do not frequently interact and, therefore, might not strongly influence each another. Tie strength also has a considerable impact on information processing (Chandler and Wieland 2010). The marketing and sociology literature (e.g., Rindfleisch and Moorman 2001; Uzzi 1996) suggests that stronger ties generate a richer information exchange. Accordingly, it can be assumed that information provided by a strong tie is processed with higher effort compared to information from a weak tie. When a Facebook user reads a product- or brand-related comment from a strong tie, her/his information processing effort might be higher and the product evaluation tends to be based on a fuller consideration of all relevant information, meaning that a negatively valenced post from a strong tie should result in a more negative product evaluation, compared to a strong tie's positively valenced post. On the other hand, we expect that information from a weak tie induces a lower processing effort level, which then facilitates the blemishing effect by referring individuals back to their initial attitude (Ein-Gar et al. 2012). In this case, the user's initial attitude towards the object will be of central concern (Herr et al. 1991) and a minor piece of conflicting information in a Facebook post from a weak tie might potentially enhance the overall evaluation of the product or brand and lead to a positive response behavior towards the negative message. Visit or purchase intention is an effectiveness measure that is highly related to product evaluation and frequently used to anticipate a response behavior to advertising messages (Daugherty et al. 2008). Hence, we assume:

H1: Tie strength moderates the impact of information valence. More specifically, negatively valenced comments from a weak tie have a positive effect on purchase or visiting intentions, if the reader knows the product and has a positive attitude towards it.

There is sufficient evidence that tie strength influences consumers' decision making processes in different situations. In a word-of-mouth context, information from strong ties has been found to be perceived by receivers as more influential in decision making than information from weak ties (Bansal and Voyer 2000; Brown and Reingen 1987; East et al. 2008). De Bruyn and Lilien (2008) observed that tie strength had a positive effect on awareness during the decision making process and triggered the recipients' interest afterwards. In a more recent study, Wang and Chang (2013) examine the effects of information valence and tie strength on selected mediating constructs and on purchase intentions. They found that product information and recommendations on Facebook from close friends are seen as more valuable, trusted and useful, and facilitate product evaluation compared to information from distant acquaintances or, to put it another way, that information provided by strong ties is perceived as having a high level of diagnosticity, which further increases purchase intention (Wang and Chang 2013). In this study, we also focus on the concept of perceived diagnosticity, which reflects the degree to which consumers consider particular brand-related comments by other consumers as helpful for evaluating products (Mudambi and Schuff 2010; Wang and Chang 2013). Accordingly, we posit that brand-related comments provided by strong-tie sources have a higher perceived diagnosticity than information provided by weak tie sources. 
$\mathrm{H} 2$ : The perceived diagnosticity of a brand-related comment is higher, if the source of information is a strong tie.

In their study, Wang and Chang (2013) focus only on positive Facebook posts and do not investigate the effects of negative information and recommendations. However, negatively valenced information has been found to be more diagnostic and influential than positively valenced information in the context of product judgments (Chevalier and Mayzlin 2006; Hamilton et al. 2014; Herr et al. 1991; Park and Lee 2009). These findings suggest a negativity bias in processing information, whereby negative information has a stronger impact on judgment and decision making than objectively equivalent positive information (Sen and Lerman 2007; Skowronski and Carlston 1989). The negativity bias argues that negative information is more diagnostic and useful for product evaluation, because negative product attributes are considered to be distinctive of low quality products, whereas positive product attributes are believed to be characteristic of both low and high quality products (Herr et al. 1991; Willemsen et al. 2011). Willemsen et al. (2011) found that the negativity effect is more pronounced for experience goods such as recreational services and restaurants, because their attributes are intangible. Therefore, performance evaluations can be verified only by experience or consumption and there is a greater chance of making an incorrect decision. In light of these arguments and findings, the following hypothesis is proposed:

H3: Negatively valenced comments about a restaurant brand induce a higher perceived diagnosticity than positively valenced posts.

In a noteworthy study, Ahluwalia (2002) questioned the robustness of the negativity effect in consumer environments and argued that it is dependent on the type of involvement. Specifically, her findings show that the nature of information processing influences the perceived diagnosticity of information (Ahluwalia 2002). Consumers tend to perceive negative brand-related information as more diagnostic than positive information when the subject's involvement motivates critical processing. Again, it can be assumed that brand-related comments from a strong tie elicit more effortful and critical processing than comments from a weak tie. Hence, we assume an interaction effect between tie strength and information valence on perceived diagnosticity:

H4: Tie strength moderates the impact of information valence on perceived diagnosticity. More specifically, negatively valenced comments have a stronger impact on perceived diagnosticity if the information source is a strong tie.
Figure 1 illustrates the hypothesized linkages among the variables under investigation. In sum, we assume that negative posts by weak ties induce the "positive effect of negative information", but only in cases where the user knows the product and has a prior positive attitude towards it (H1). We have not included the user's product knowledge or attitude towards the restaurant in the conceptual model, because a prior positive attitude towards the brand is crucial for testing $\mathrm{H} 1$ but not for testing $\mathrm{H} 2$ to H4. Additionally, we suggest that information posted by a strong tie is perceived as more diagnostic than information from a weak tie (H2). Further, according to the negativity bias, we assume that negatively valenced posts are perceived as more diagnostic than positively valenced posts (H3). Finally, we suggest an interaction effect and argue that negative brand-related information is perceived more diagnostic when it is posted by a strong tie (H4). We test the hypothesized effects in two studies. The primary focus of study 1 is on the positive effect of negative information when the previous attitude towards the restaurant brand is highly positive. In study 2 , we refocus the perspective and only consider Facebook users who do not know the restaurant chain at all.

\section{Study 1}

The purpose of the first online experiment was to test the assumption that, under certain conditions, negative information can have positive effects on consumers' response behavior to the negative message. In particular, the focus of this experiment was on the hypothesized interaction effect of valence and tie strength on visiting intentions, assuming a positive effect of negative posts from weak ties when the reader knows the product and has a positive attitude towards it $(\mathrm{H} 1)$. Additionally, we test the impact of brand-related information on the perceived diagnosticity of the post. Specifically, we investigate whether negative Facebook posts or posts from strong ties induce higher levels of diagnosticity, addressing $\mathrm{H} 2$ and $\mathrm{H} 3$, as well as the proposed interaction effect of valence and tie strength in this context (H4).

\section{Design}

To test the proposed hypotheses, we conducted a 2 valence (positive vs. negative Facebook post) x 2 tie strength (strong vs. weak ties) between-subjects online experiment with 82 Facebook users. With a careful isolation of the variables under consideration, the aim was to obtain an experimental design that allows for estimating the effects of valence and tie strength. A Facebook comment that described a visit to a moderately well known restaurant chain was chosen, as it was deemed to be an appropriate post that might also appear on Facebook in reality. The chosen restaurant brand had 
Fig. 1 Conceptual model

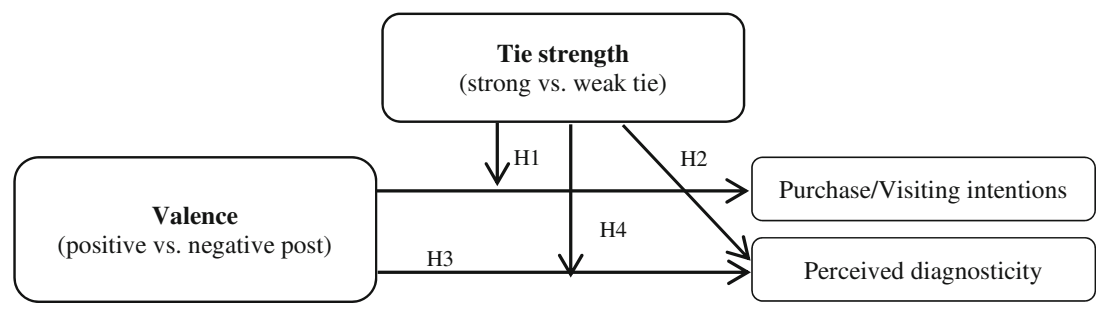

recently opened its first outlet in the region and had invested heavily in regional advertising in advance. As the participants' positive pre-attitude towards the restaurant is of central importance for the positive effect of negative information to occur, this experiment focuses only on Facebook users who knew the restaurant brand. A scenario was created that revealed either a positive or a negative comment regarding a visit to a restaurant posted by a close friend or distant acquaintance (reflecting the different levels of tie strength). The English translations of the positive and negative Facebook posts are presented below (see Figs. 2 and 3), the originals were in German.

\section{Procedure}

The experiment was conducted online, using EFS Survey from Questback. The participants were recruited via Facebook and the link to the online survey was posted on the Facebook pages of some of the research team members. Participants were also encouraged to actively forward the link to their friends. Additionally, graduate students at a mid-sized Austrian University were invited to participate in the online experiment. After clicking on the link leading to the online questionnaire, the participants were informed that the purpose of the survey was to gain insights into the consequences of customer engagement behavior on Facebook. To make sure that only Facebook users fill in the questionnaire, the participants were first asked if they have a Facebook account, followed by questions on their Facebook usage behavior. In order to evaluate the attitude towards the restaurant chain, we assessed the user's attitude before the manipulation of the Facebook post. To minimize priming effects, the user was confronted with different restaurant chains and had to indicate, which of the restaurant chains s/he knew and what his/her attitude towards the restaurant was. Afterwards, participants were asked to indicate the first name of three very close friends (strong ties) or the first name of three distant acquaintances (weak ties) on Facebook. Participants in the strong tie condition were briefed that very close friends are those people they interact most with, and who are very well known and trusted. Similarly, participants in the weak tie condition were informed that distant acquaintances are people they interact least with and who are not very well known. Subsequently, participants were told to imagine that they have discovered a post by the respective strong or weak tie (name of the friend or acquaintance was indicated) on their Facebook wall. The comment revealed that [name of close friend / name of distant acquaintance] had visited the restaurant the previous evening and included additional positive or negative information on the overall experience, ambience and staff, as well as the logo of the restaurant chain (see Figs. 2 and 3). Users were randomly assigned to one of four conditions: 18 participants were exposed to the positive post from a strong tie condition, 22 to the positive post from a weak tie condition, 18 to the negative post from a strong tie condition and 24 to the negative post from a weak tie condition. After the users had seen this manipulated product information, they were asked to fill in the remaining questionnaire.

\section{Manipulation check}

To check if the manipulations of the Facebook posts worked, we adapted three items from the construct "tie strength" by Mittal et al. (2008) (items are reported in the Appendix). Participants perceived the relationship to strong ties as closer $\left(\mathrm{M}_{\text {strong }}=6.370, \mathrm{SE}=.133, \mathrm{CI}_{95 \%}=6.100-6.641\right)$ compared to weak ties $\left(\mathrm{M}_{\mathrm{weak}}=2.022, \mathrm{SE}=.182, \mathrm{CI}_{95 \%}=1.655-\right.$ 2.389). As the Levene statistic is significant and thus the assumption of homogeneity of variance is violated, we report the Welch F-ratio: $\mathrm{F}(1,77.510)=370.874, p<.001$, indicating a significant difference between the two groups and confirming that the manipulation of tie strength was successful.

Furthermore, to check if the manipulation of the valence of the Facebook post worked, we asked the participants how positively or negatively they evaluate the Facebook post they received $(1=$ very negative $-7=$ very positive $)$. Participants who saw a positive post rated the post as more positive $\left(\mathrm{M}_{\text {positive }}=4.53, \mathrm{SE}=.224, \mathrm{CI}_{95 \%}=4.07-4.98\right)$ compared to users who received a negative post $\left(\mathrm{M}_{\text {negative }}=2.31\right.$, $\left.\mathrm{SE}=.195, \mathrm{CI}_{95 \%}=1.91-2.70 ; \mathrm{F}(1,77)=55.670, p<.001\right)$.

Yesterday we had dinner at
staff, an absolute disaster - not recommendable at all. I definitely never
go there again.
Logo of the restaurant
Gefällt mir · Kommentieren - Teilen

Fig. 2 Negative manipulated Facebook post 
We enjoyed an absolutely delicious dinner at 5 yesterday. Great ambience, very friendly staff, a smash hit - absolutely recommendable. I definitely have to go there again.

\section{Logo of the restaurant}

Gefällt mir · Kommentieren - Teilen

Fig. 3 Positive manipulated Facebook post

Summing up, the differences between participants for all treatments were significant, indicating a successful experimental manipulation.

\section{Measures}

Established scales were used and adapted to a restaurant context where needed to measure each of the investigated constructs. Three items from Wang et al. (2012) gauged the user's intentions of visiting the restaurant. Additionally, we adapted a two-item scale from Qiu et al. (2012) to measure the diagnosticity of the Facebook post. It can be assumed that the user's attitude towards Facebook plays a major role in determining whether or not the user participates in the Facebook community, reads and pays attention to posts from his/her friends. Thus, we included attitude towards Facebook as covariate and measured it with three items, borrowed from Lai and Li (2005). Furthermore, as we assume that the user's previous attitude towards the restaurant is of central concern, we also controlled for attitude towards the restaurant in the analyses. Before participants were directed to the manipulated Facebook post, we used a single item and asked them what their overall attitude towards the restaurant is. A prior test of homogeneity for the covariate showed that the regression slopes do not significantly differ between the groups for both dependent variables. Further details are provided in Table 1. All measurement items (English translation) are provided in the Appendix.

\section{Participants}

Eighty-two Facebook users (60 female; average age = 28.95 years, $\mathrm{SD}=9.10$ ) participated in the online questionnaire. We checked whether age or gender showed any

Table 1 Study 1 - descriptive statistics of the dependent variables and covariate

\begin{tabular}{clclc}
\hline & & Mean & $\begin{array}{l}\text { Std. } \\
\text { deviation }\end{array}$ & $\begin{array}{l}\text { Cronbach } \\
\text { alpha }\end{array}$ \\
\hline $\begin{array}{c}\text { Dependent } \\
\text { variables }\end{array}$ & Diagnosticity & 3.531 & 2.007 & .984 \\
Covariate & Attitude towards & 4.346 & 1.734 & .964 \\
& Facebook & 3.919 & 1.315 & .816 \\
\hline
\end{tabular}

significant differences among the random groups. ANOVA and Chi-square tests yielded no significant differences. Participants reported spending 108.23 min per day on Facebook on average and having an average of 373 Facebook friends. We primarily addressed Austrian users from urban areas, as the restaurant chain is currently only located in the major cities of Vienna, Innsbruck and, most recently, Graz.

\section{Results and discussion}

We conducted two $2 \times 2$ ANCOVAs with valence and tie strength as the independent variables. No MANCOVAs were used, since the two dependent variables showed no significant correlation.

Visiting intentions The mean of visiting intentions for users who received a negative post $\left(\mathrm{M}_{\text {negative }}=4.635\right)$ is higher compared to users who saw a positive post $\left(\mathrm{M}_{\text {positive }}=4.005\right.$; $\mathrm{F}(1,77)=3.026, p=.086)$, but the difference for the main effect of information valence is not significant. However, there was a significant interaction effect of the Facebook post's valence and tie strength, $\mathrm{F}(1,77)=10.111, p<.01$ (see Table 2). Specifically, while in the condition of a positive post, the mean visiting intention is significantly higher for posts from strong ties $\left(\mathrm{M}_{\text {strong }}=4.553 ; \mathrm{M}_{\text {weak }}=3.456 ; \mathrm{F}(1,77)=4.254\right.$, $p<0.05$ ), while in the condition of a negative post, the mean visiting intention is significantly higher for posts from weak ties $\left(\mathrm{M}_{\text {strong }}=4.027 ; \mathrm{M}_{\text {weak }}=5.244 ; \mathrm{F}(1,77)=5.660\right.$, $p<0.05)$, as depicted in Fig. 4, thus confirming H1.

Diagnosticity Since the Levene statistic is significant $(p=.004)$, we also looked at the Hartley's Homogeneity of Variance Test. Hartely's Fmax is the ratio of the variances between the groups with the highest and the lowest variance (e.g., see Field 2013). The critical value is larger than the $\mathrm{F}_{\max }=2.875$, thus we may assume that the groups have the same variances. The mean perceived diagnosticity of a Facebook post for users who received a post from a strong tie $\left(\mathrm{M}_{\text {strong }}=4.086\right)$ is significantly higher compared to users

Table 2 Study 1 - results of ANCOVAs

\begin{tabular}{|c|c|c|c|c|c|c|c|}
\hline & \multirow[t]{2}{*}{ DVs sources } & \multicolumn{3}{|c|}{$\begin{array}{l}\text { Visiting } \\
\text { intentions }\end{array}$} & \multicolumn{3}{|c|}{$\begin{array}{l}\text { Perceived } \\
\text { diagnosticity }\end{array}$} \\
\hline & & $\mathrm{df}$ & $\mathrm{F}$ & $\mathrm{p}$ & $\mathrm{df}$ & $\mathrm{F}$ & $\mathrm{p}$ \\
\hline \multirow[t]{2}{*}{ Main effects } & Valence & 1 & 3.026 & .086 & 1 & 1.597 & .210 \\
\hline & Ties & 1 & .026 & .873 & 1 & 4.916 & .030 \\
\hline Interaction effect & Valence*ties & 1 & 10.111 & .002 & 1 & .028 & .868 \\
\hline
\end{tabular}




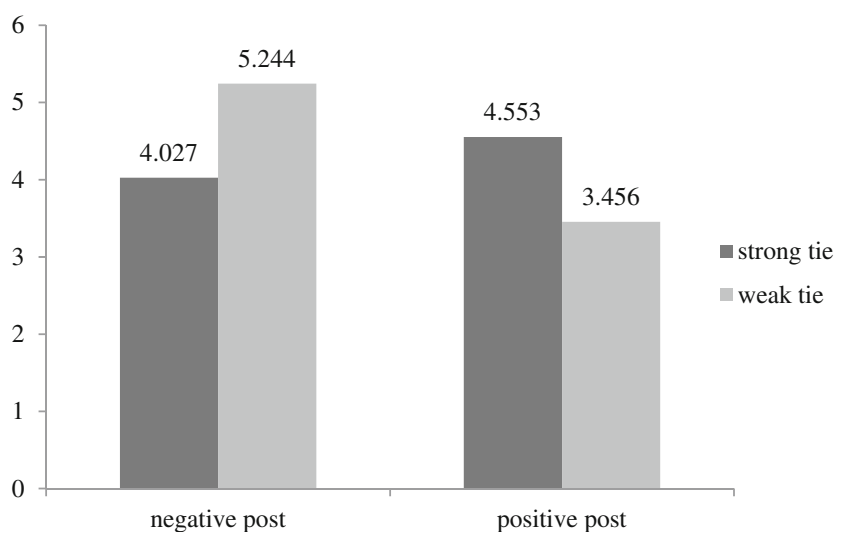

Fig. 4 Interaction effect of valence and tie strength on visiting intention

who saw a post from a weak tie $\left(\mathrm{M}_{\text {weak }}=3.085 ; \mathrm{F}(1\right.$, $77)=4.916, p<.05$ ). Thus, we can report that $\mathrm{H} 2$ is supported.

The main aim of the first experiment was to analyze, if negative information can have positive effects and increase visiting intentions with regard to a restaurant, in particular if weak ties post the information. For users who are familiar with the restaurant, we observed a significant interaction effect, revealing that visiting intentions are the highest, if the Facebook user reads a negative post by a distant acquaintance. Looking at posts from strong ties, it can be seen that a positive post from a strong tie induces higher visiting intentions than a negative post. This result goes in line with our assumption that the blemishing effect only works for weak ties. Participants in this study also showed relatively high attitude scores towards the restaurant before reading the manipulated posts $(M=5.56, \mathrm{SD}=1.156)$. Hence, the findings confirm our assumption that when users who have a previous positive attitude towards the brand get a small piece of negative brand-related information from a weak tie (i.e., in a situation where processing effort is expected to be lower and thus the following brand evaluation is based on a weaker consideration of all relevant information), an intensification of the initial positive impression of the target brand is the consequence.

Next, the significant main effect of tie strength on perceived diagnosticity reveals that users ascribe higher levels of diagnosticity to posts from strong ties, supporting $\mathrm{H} 2$. This result is in line with previous research indicating that messages from strong tie friends have a powerful influence on consumer decision making (Wang and Chang 2013). Against our expectations, when the participant knows the restaurant, she/he does not perceive negatively valenced Facebook posts as having significantly more diagnostic value than positively valenced posts. Hence, H3 is not supported by our data. As suggested, negatively valenced posts from strong ties have the highest level of diagnosticity. However, as the interaction effect is not significant, H4 was not confirmed.

\section{Study 2}

\section{Purpose}

The focus of study 1 was on the positive effect of negative information when the previous attitude towards the restaurant was highly positive. In study 2 , we change the perspective and concentrate on Facebook users who do not know the restaurant chain at all. Thus, we analyze the consequences of brand-related Facebook posts for an unknown product to corroborate our assumption that the positive effect of negative information will only occur, if the user knows the product and has a positive attitude towards it (H1). In particular, we assume that in cases where the user does not know the restaurant brand, positive brand-related information from strong tie sources will dominate the effect on visiting intentions with regard to the restaurant, since strong ties are regarded as trusted and well-known relationships, having a greater influence on the receiver's product evaluations compared to weak tie relationships. Further, we also investigate whether or not negative posts or posts from strong tie sources induce higher levels of diagnosticity (addressing $\mathrm{H} 2$ and $\mathrm{H} 3$ ), as well as the assumption that negatively valenced comments have a stronger impact on perceived diagnosticity, if the information source is a strong tie (H4).

To address these assumptions, we again conducted a 2 valence (positive vs. negative) $\times 2$ tie strength (strong vs. weak tie) between-subject online experiment with 65 Facebook users. We followed the same procedure as in the first experiment. Now, participants who did not know the restaurant brand were randomly assigned to one of the following conditions: 14 participants were exposed to the positive post from a strong tie condition, 16 to the positive post from a weak tie condition, 20 to the negative post from a strong tie and 15 to the negative post from a weak tie condition.

The same manipulation checks were included to ensure that the manipulations of the Facebook posts were being perceived as intended. Participants perceived the relationship to strong ties as closer $\left(\mathrm{M}_{\text {strong }}=6.667, \mathrm{SE}=.099, \mathrm{CI}_{95 \%}=6.466-\right.$ 6.867) compared to weak ties $\left(\mathrm{M}_{\text {weak }}=2.441, \mathrm{SE}=.302\right.$, $\left.\mathrm{CI}_{95 \%}=1.823-3.058\right)$. As the Levene statistic is significant and thus assumption of homogeneity of variance is violated, we report the Welch F-ratio: $\mathrm{F}(1,36.339)=176.674, p<.001)$. Participants who saw a positive post evaluated the post as more positive $\left(\mathrm{M}_{\text {positive }}=4.50, \mathrm{SE}=.331, \mathrm{CI}_{95 \%}=3.82-5.18\right)$ compared to users who received a negative post $\left(\mathrm{M}_{\text {negative }}=2.97, \mathrm{SE}=.294, \mathrm{CI}_{95 \%}=2.37-3.57 ; \mathrm{F}(1\right.$, $59)=12.030, p=.001)$. Again, the differences between participants for all treatments were significant, indicating a successful experimental manipulation. 


\section{Measures}

We used the same measurements as in study 1 for the user's visiting intentions with regard to the restaurant, the perceived diagnosticity of the Facebook post and the user's attitude towards Facebook, which served once more as covariate. A prior test of homogeneity of the covariate showed that the regression slope of the covariate does not significantly differ between the groups for both dependent variables. Descriptive statistics of the dependent variables and the covariate are provided in Table 3.

\section{Participants}

Sixty-five Facebook users ( 40 female; average age $=29.15$ years, $\mathrm{SD}=7.821$ ) participated in the online questionnaire that was again distributed via snowball principle on Facebook. First of all, graduate students at a mid-sized Austrian University situated in a region where the restaurant has no branch (yet), were invited to participate. This time, the focus of the experiment was solely on Facebook users who did not know the restaurant, thus users who knew the restaurant were not included in the analyses. Participants reported spending 65.43 min per day on Facebook on average and having an average of 260 friends on Facebook. Altogether, we addressed mainly Austrian users from rural areas where the restaurant chain has no branch presence and the likelihood of reaching Facebook users who were unfamiliar with the restaurant was higher.

\section{Results and discussion}

We conducted two $2 \times 2$ ANCOVAs with valence and tie strength as the independent variables.

Visiting intentions with regard to the restaurant For Facebook users who do not know the restaurant brand at all, we did not find any significant differences between the groups. Positive Facebook posts $\left(\mathrm{M}_{\text {positive }}=3.687\right)$ resulted in higher visiting intention scores compared to negative posts $\left(\mathrm{M}_{\text {negative }}=2.985\right)$, but the difference was not significant $\mathrm{F}(1$, $60)=3.391, p=.07$.

Table 3 Study 2 - descriptive statistics of the dependent variables and covariate

\begin{tabular}{clclc}
\hline & & Mean & $\begin{array}{l}\text { Std. } \\
\text { deviation }\end{array}$ & $\begin{array}{l}\text { Cronbach } \\
\text { alpha }\end{array}$ \\
\hline $\begin{array}{c}\text { Dependent } \\
\text { variables }\end{array}$ & Diagnosticity & 3.923 & 2.014 & .989 \\
Covariate & Attitude towards & 3.282 & 1.567 & .938 \\
& Facebook & 3.462 & 1.287 & .853 \\
\hline
\end{tabular}

Diagnosticity of the Facebook post There was a significant main effect of tie strength on the users' perceived diagnosticity of the Facebook post. The mean diagnosticity for users who received a post by a strong tie $\left(\mathrm{M}_{\text {strong }}=4.416\right)$ is higher compared to users who saw a post from a weak tie $\left(\mathrm{M}_{\text {weak }}=3.269\right.$; $\mathrm{F}(1,60)=6.115, p<.05)$, confirming H2. Further, there was a significant interaction effect of the Facebook post's valence and tie strength, $\mathrm{F}(1,60)=4.367, p<.05$ (see Table 4). Specifically, while in the condition of a positive post, there is no significant difference for the impact of a post by a strong or weak tie $\left(\mathrm{M}_{\text {strong }}=3.906 ; \mathrm{M}_{\text {weak }}=3.729 ; \mathrm{F}(1,60)=.069, p>.1\right)$, in the condition of a negative post, the mean diagnosticity is significantly higher for posts from strong ties $\left(\mathrm{M}_{\text {strong }}=4.925\right.$; $\left.\mathrm{M}_{\text {weak }}=2.810 ; \mathrm{F}(1,60)=11.159, p<0.05\right)$, as depicted in Fig. 5, thus confirming $\mathrm{H} 4$.

The results reveal that for users who are not familiar with the restaurant brand, positive posts have a higher impact on visiting intentions, although the difference is not significant. As we have suggested that the positive effect of a negatively valenced Facebook comment on visiting intentions requires brand knowledge and a prior positive brand attitude, this result also can be interpreted as supportive of H1. Furthermore, as suggested in $\mathrm{H} 2$, users perceive posts from strong ties as more diagnostic than posts from weak ties. Indeed, this result confirms the proposition that brand-related information from close friends is seen as more valuable, facilitating evaluations in a situation where the individual has no attitudes formed a priori toward the target brand. Contrary to our expectations, the main effect of valence on perceived diagnosticity was not significant. Hence, H3 had to be rejected. However, as suggested, tie strength moderates the impact of information valence on perceived diagnosticity. In particular, a negatively valenced comment from a close friend has a stronger impact on perceived diagnosticity, confirming $\mathrm{H} 4$.

\section{General discussion}

\section{Summary and implications of the findings}

In times of omnipresent mass media, it is less a problem of getting access to sufficient information but rather an issue of

Table 4 Study 2 - results of ANCOVAs

\begin{tabular}{|c|c|c|c|c|c|c|c|}
\hline & \multirow[t]{2}{*}{$\begin{array}{l}\text { DVs } \\
\text { sources }\end{array}$} & \multicolumn{3}{|c|}{$\begin{array}{l}\text { Visiting } \\
\text { intentions }\end{array}$} & \multicolumn{3}{|c|}{$\begin{array}{l}\text { Perceived } \\
\text { diagnosticity }\end{array}$} \\
\hline & & $\mathrm{df}$ & $\mathrm{F}$ & $\mathrm{p}$ & $\mathrm{df}$ & $\mathrm{F}$ & $\mathrm{p}$ \\
\hline \multirow[t]{2}{*}{ Main effects } & Valence & 1 & 3.391 & .070 & 1 & .012 & .914 \\
\hline & Ties & 1 & .033 & .857 & 1 & 6.115 & .016 \\
\hline Interaction effects & Valence $^{*}$ ties & 1 & 1.540 & .220 & 1 & 4.367 & .041 \\
\hline
\end{tabular}




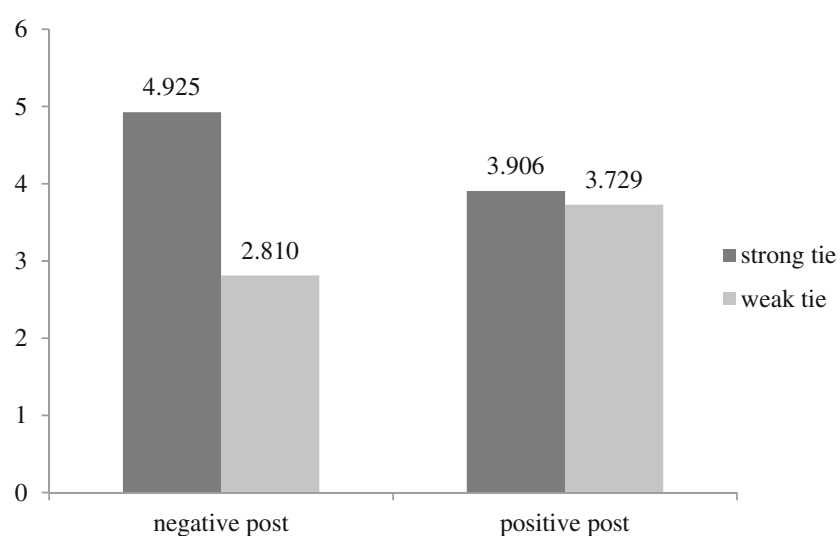

Fig. 5 Interaction effect of valence and tie strength on perceived diagnosticity of the Facebook post

filtering out untrustworthy data from an overwhelming mass of facts and figures (Takac et al. 2011). Consumers need cues to evaluate the relevance and trustworthiness of product- and brand-related information on social networking sites (Pan and Chiou 2011). If the user believes and adopts the recommendations, it will result in a change of attitudes, beliefs and actions (Chang and Wu 2014). The current study provides a first attempt to analyze potential consequences of positively and negatively valenced customer engagement behavior on Facebook.

Our research questions scrutinized whether and under which conditions negative brand-related information can have positive effects in the context of customer interaction on social media platforms. Imagine that you are reading through your Facebook news feeds and you see that one of your Facebook friends went to a restaurant and had a horrific evening there. How does this piece of negative information affect your personal intentions to visit this restaurant? Is this piece of information useful or valuable for you at all? These questions point to the need to examine the outcomes that result from customers' brand-related interactions in OSNs. In line with previous research (e.g., Ein-Gar et al. 2012), we assumed that there would be a difference, depending on whether the user already had an initial (positive) attitude towards the object or not. Study 1 addresses this issue by focusing solely on participants who were familiar with the target restaurant brand. The analysis indicates that users familiar with the mentioned restaurant had initial high attitude scores towards the restaurant chain. The results show, similar to the findings of Ein-Gar et al. 2012 that a small dose of negative information posted by distant acquaintances (i.e., weak ties) indeed significantly increases the readers visiting intentions. However, no such positive effect was found for negative brand-related information posted by a strong tie. Furthermore, users tend to perceive a comment about a restaurant they know from a close friend as more diagnostic than a comment from a distant acquaintance, independent of the valence of the post. These findings are consistent with those of other studies in the context of electronic word-of-mouth, which found that strong tie information sources were perceived to be more useful (Park and Lee 2009; Wang and Chang 2013; Willemsen et al. 2011).

Using the same methodology as in study 1, but focusing on Facebook users who are not familiar with the restaurant chain, the second experiment suggests the importance of positive information and strong ties. In contrast to the findings of the first experiment, users who are not familiar with the restaurant report higher levels of visiting intention when reading a positive post, but the difference is not significant. These findings also support $\mathrm{H} 1$, as we expected the positive effect of negative information to occur only in instances when the user knows the brand and has a prior positive attitude towards it. For an unknown restaurant we would not have expected a positive effect of (a small piece of) negative information, because more complex processing is required when there is no remembered information concerning the product or brand (Biehal and Chakravarti 1986). Besides, for consumers who do not know the restaurant a comment from a strong tie is perceived as more useful or diagnostic compared to a comment posted by a weak tie. This result is in agreement with the findings of Wang and Chang (2013), which showed that information and recommendations provided by close friends are perceived as having a high level of diagnosticity. Moreover, our results reveal a significant interaction effect for valence and tie strength on perceived diagnosticity. In particular, negative posts from strong ties induce the highest levels of diagnosticity.

The findings of the current study suggest that tie strength is an important reference point for Facebook users when it comes to the evaluation of brand-related information. Furthermore, tie strength also denotes an attractive element for advertising on social networking sites (Wen et al. 2009). Weak ties are obviously not that trusted, potentially leading to a reverse effect of polarizing an initial positive attitude towards the brand. However, in a situation when users have no prior information and no previously formed attitude toward the mentioned restaurant brand it can be observed that they revert to the familiarity of close personal relationships. Our results emphasize that particularly information from strong ties is perceived as highly diagnostic and influential. This is in line with previous research and social capital theory, which considers strong ties as trusted relationships that provide indepth information that can be relied upon (e.g., Brown and Reingen 1987; Granovetter 1983; Gubbins and MacCurtain 2008; Tsai and Ghoshal 1998).

The current research contributes to the literature on online social networks and customer engagement behavior in several ways. First of all, this research sheds light on possible consequences brand-related comments of interactive customers can have on Facebook. Additionally, this research pinpoints the importance of the users' ties in a social media environment and the effects brand-related comments of different ties can 
have on the users' decision making. Furthermore, our study is consistent with the rather novel assumption of potential positive effects of negative product information and thus offers further evidence for this effect in a social media context.

Concluding, we want to indicate some managerial implications of our study. The main conclusion is that not all types of negative information that are circulating in social media must per se be detrimental for the image of the brand or the company. As the results show, it depends on the circumstances. OSNs are a highly personalized environment and the same piece of negative information posted by different friends or contacts might have different consequences that can even result in an opposite positive effect for the mentioned product or company. The current research suggests that companies can actually profit from occasional negatively valenced comments on social networking sites when their brand is well-known and popular. As highlighted by Ein-Gar et al. (2012), even though information acquisition can no longer be controlled by the companies, there remain plenty of possibilities in an online social media environment for the companies to present themselves, staying in control of the information and being actively involved in this process. In addition, the results highlight that Facebook is a suitable means to spread information about unknown products (e.g., by applying seeding strategies and viral marketing), since positive posts about unknown products positively affect product evaluation. As pointed out by Wang and Chang (2013), marketers can approach appropriate customers to recommend a product to their Facebook friends, expecting that those recommendations would have a positive impact on purchase intentions.

\section{Limitations and further research}

Although our findings are encouraging and useful, their applicability must be considered in the light of some of the study's limitations. First, our study focuses only on two dependent variables, visiting intentions and perceived diagnosticity. However, brand-related posts on Facebook may affect other constructs that are of central interest. For example, what is the impact on brand attitude and brand trust or on actual behavioral reactions? Second, we only manipulated the valence and the sender of the Facebook posts. Yet, as previous research shows (e.g., Ganster et al. 2012; Lo 2008; Park et al. 2014), non-verbal cues are commonly used for online communication, which we did not include in either the positively or in the negatively valenced comments. Thus, future research should analyze, whether those cues trigger different reactions or intensify the observed effects. Third, our survey concentrated solely on one restaurant brand. Hence, we cannot suggest that the effects would be the same for other types of products. Follow-up surveys should take this into consideration. Fourth, we acknowledge that the small sample size represents a major limitation of this study, limiting statistical power. One aspect, which may justify the small sample size, is that the study design is novel and as such addresses the issue as a first step in understanding its implications. Fifth, we also recognize that the generalizability of the results is limited due to the fact that participants were not observed in a real Facebook environment but in an artificial experimental setting. People might behave differently when they use Facebook in reality rather than just answering questions about it ("how would you behave...?"). We encourage future research in this area to establish a setting where Facebook users can be observed in a "real" setting, notwithstanding that it would require considerable effort. Finally, we applied a snowball principle to spread our questionnaire on Facebook. This non-random nature of data collection further limits the generalizability of the findings. Future research studies should address those points accordingly.

Acknowledgments Open access funding provided by Universitaet Klagenfurt.

\section{Appendix}

\begin{tabular}{|c|c|c|}
\hline \multirow[t]{2}{*}{$\begin{array}{l}\text { Dependent } \\
\text { variables }\end{array}$} & $\begin{array}{l}\text { Visiting } \\
\text { intention }\end{array}$ & $\begin{array}{l}\text { What is the plausibility that you would } \\
\text { visit [name of the restaurant]? } \\
\text { (1) unlikely - (7) likely } \\
\text { (1) uncertain - (7) certain } \\
\text { (1) definitely not - (7) definitely }\end{array}$ \\
\hline & Diagnosticity & $\begin{array}{l}\text { Please evaluate the following } \\
\text { statements: } \\
\text { Overall, how useful and helpful is the } \\
\text { information provided by [name of } \\
\text { friend] to judge [name of the } \\
\text { restaurant]? } \\
\text { (1) not useful at all - (7) very useful } \\
\text { (1) not helpful at all - (7) very helpful }\end{array}$ \\
\hline Covariate & $\begin{array}{l}\text { Attitude } \\
\text { towards } \\
\text { Facebook }\end{array}$ & $\begin{array}{l}\text { Please evaluate the following } \\
\text { statements: } \\
\text { In my opinion, it is desirable to use } \\
\text { Facebook. } \\
\text { I think it is good for me to use } \\
\text { Facebook. } \\
\text { Overall, my attitude towards Facebook } \\
\text { is favorable. } \\
\text { (1) strongly disagree - (7) strongly } \\
\text { agree }\end{array}$ \\
\hline \multirow[t]{2}{*}{$\begin{array}{l}\text { Manipulation } \\
\text { check }\end{array}$} & Tie strength & $\begin{array}{l}\text { How would you evaluate your } \\
\text { relationship with [name of friend]? } \\
\text { (1) not close at all }-(7) \text { very close } \\
\text { (1) very weak }-(7) \text { very strong } \\
\text { (1) not familiar at all }-(7) \text { very familiar }\end{array}$ \\
\hline & Valence & $\begin{array}{l}\text { How would you evaluate the post from } \\
\text { [name of friend]? } \\
\text { The Facebook post from [name of } \\
\text { friend] was (1) very negative - (7) } \\
\text { very positive }\end{array}$ \\
\hline
\end{tabular}


Open Access This article is distributed under the terms of the Creative Commons Attribution 4.0 International License (http:// creativecommons.org/licenses/by/4.0/), which permits unrestricted use, distribution, and reproduction in any medium, provided you give appropriate credit to the original author(s) and the source, provide a link to the Creative Commons license, and indicate if changes were made.

\section{References}

Ahluwalia, R. (2002). How prevalent is the negativity effect in consumer environments? Journal of Consumer Research, 29(2), 270-279. doi: $10.1086 / 341576$.

Bansal, H. S., \& Voyer, P. A. (2000). Word-of-mouth processes within a services purchase decision context. Journal of Service Research, 3(2), 166-177.

Berger, J., Sorensen, A. T., \& Rasmussen, S. J. (2010). Positive effects of negative publicity: when negative reviews increase sales. Marketing Science, 29(5), 815-827.

Biehal, G., \& Chakravarti, D. (1986). Consumers' use of memory and external information in choice: macro and micro perspectives. Journal of Consumer Research, 12(4), 382-405. doi:10.2307/ 254300 .

Bitter, S., Grabner-Kräuter, S., \& Breitenecker, R. J. (2014). Customer engagement behaviour in online social networks - the Facebook perspective. International Journal of Networking and Virtual Organisations, 14(1/2), 197-220.

Brass, D. J., Galaskiewicz, J., Greve, H. R., \& Tsai, W. (2004). Taking stock of networks and organizations: a multilevel perspective. The Academy of Management Journal, 47(6), 795-817. doi:10.2307/ 20159624.

Brodie, R. J., Hollebeek, L. D., Juric, B., \& Ilic, A. (2011). Customer engagement: conceptual domain, fundamental propositions, and implications for research. Journal of Service Research, 14(3), 252271. doi:10.1177/1094670511411703.

Brown, J. J., \& Reingen, P. H. (1987). Social ties and word-of-mouth referral behavior. Journal of Consumer Research, 14(3), 350-362.

Burt, R. S. (1997). A note on social capital and network content. Social Networks, 19(4), 355-373. doi:10.1016/s0378-8733(97)00003-8.

Chandler, J. D., \& Wieland, H. (2010). Embedded relationships: implications for networks, innovation, and ecosystems. Journal of Business Market Management, 4(4), 199-215.

Chang, H. H., \& Wu, L. H. (2014). An examination of negative e-WOM adoption: brand commitment as a moderator. Decision Support Systems, 59, 206-218. doi:10.1016/j.dss.2013.11.008.

Chang, Y. P., \& Zhu, D. H. (2012). The role of perceived social capital and flow experience in building users' continuance intention to social networking sites in China. Computers in Human Behavior, 28(3), 995-1001. doi:10.1016/j.chb.2012.01.001.

Cheung, C. M. K., \& Thadani, D. R. (2012). The impact of electronic word-of-mouth communication: a literature analysis and integrative model. Decision Support Systems, 54(1), 461-470. doi:10.1016/j. dss.2012.06.008.

Chevalier, J. A., \& Mayzlin, D. (2006). The effect of word of mouth on sales: online book reviews. Journal of Marketing Research, 43(3), 345-354.

Daugherty, T., Li, H., \& Biocca, F. (2008). Consumer learning and the effects of virtual experience relative to indirect and direct product experience. Psychology and Marketing, 25(7), 568-586.

De Bruyn, A., \& Lilien, G. L. (2008). A multi-stage model of word-ofmouth influence through viral marketing. International Journal of Research in Marketing, 25(3), 151-163. doi:10.1016/j.ijresmar. 2008.03.004.
DeAndrea, D. C., Ellison, N. B., LaRose, R., Steinfield, C., \& Fiore, A. (2012). Serious social media: on the use of social media for improving students' adjustment to college. The Internet and Higher Education, 15(1), 15-23. doi:10.1016/j.iheduc.2011.05.009.

East, R., Hammond, K., \& Lomax, W. (2008). Measuring the impact of positive and negative word of mouth on brand purchase probability. International Journal of Research in Marketing, 25(3), 215-224. doi:10.1016/j.ijresmar.2008.04.001.

Ein-Gar, D., Shiv, B., \& Tormala, Z. L. (2012). When blemishing leads to blossoming: the positive effect of negative information. Journal of Consumer Research, 38(5), 846-859. doi:10.1086/660807.

Facebook (2013). Annual Report 2012. Retrieved from.

Facebook. (2015). Company Info. Retrieved from http://newsroom.fb. com/company-info/.

Field, A. (2013). In M. Carmichael (Ed.), Discovering statistics using IBM SPSS statistics (4th ed.). London: Sage Publications Ltd.

Ganster, T., Eimler, S. C., \& Krämer, N. C. (2012). Same same but different!? The differential influence of smilies and emoticons on person perception. Cyberpsychology \& Behavior, 15(4), 226-230.

Grabner-Kräuter, S., \& Bitter, S. (2015). Trust in online social networks: a multifaceted perspective. Forum for Social Economics, 44(1), 4868. doi:10.1080/07360932.2013.781517.

Granovetter, M. S. (1973). The strength of weak ties. The American Journal of Sociology, 78(6), 1360-1380. doi:10.1086/225469.

Granovetter, M. (1983). The strength of weak ties: A network theory revisited. Sociological Theory, 1, 201-233. Retrieved from http:// www.jstor.org/stable/202051.

Gubbins, C., \& MacCurtain, S. (2008). Understanding the dynamics of collective learning: the role of trust and social capital. Advances in Developing Human Resources, 10(4), 578-599. doi:10.1177/ 1523422308320372

Gummerus, J., Liljander, V., Weman, E., \& Pihlström, M. (2012). Customer engagement in a Facebook brand community. Management Research Review, 35(9), 857-877. Retrieved from 10.1108/01409171211256578.

Hamilton, R., Vohs, K. D., \& McGill, A. L. (2014). We'll be honest, this won't be the best article you'll ever read: the use of dispreferred markers in word-of-mouth communication. Journal of Consumer Research, 41(1), 197-212.

Herr, P. M., Kardes, F. R., \& Kim, J. (1991). Effects of word-of-mouth and product-attribute information on persuasion: an accessibilitydiagnosticity perspective. Journal of Consumer Research, 17(4), 454-462. doi:10.2307/2626839.

Hess, T., Lang, K., \& Xu, S. (2011). Social embeddedness and online consumer behavior. Electronic Markets, 21(3), 157-159. doi:10. 1007/s12525-011-0071-1.

Hollebeek, L. D. (2012). The customer engagement/value interface: an exploratory investigation. Australasian Marketing Journal; AMJ. doi:10.1016/j.ausmj.2012.08.006.

Hollebeek, L. D. (2013). The customer engagement/value interface: an exploratory investigation. Australasian Marketing Journal; AMJ, 21(1), 17-24. doi:10.1016/j.ausmj.2012.08.006.

Hollebeek, L. D., \& Chen, T. (2014). Exploring positively- versus negatively-valenced brand engagement: a conceptual model. The Journal of Product and Brand Management, 23(1), 62-74. doi:10. 1108/JPBM-06-2013-0332.

Jahn, B., \& Kunz, W. (2012). How to transform consumers into fans of your brand. Journal of Service Management, 23(3), 344-361. Retrieved from 10.1108/09564231211248444.

Kabadayi, S., \& Price, K. (2014). Consumer - brand engagement on Facebook: liking and commenting behaviors. Journal of Research in Interactive Marketing, 8(3), 203-223. doi:10.1108/JRIM-122013-0081.

Kempf, D. S., \& Smith, R. E. (1998). Consumer processing of product trial and the influence of prior advertising: a structural modeling 
approach. Journal of Marketing Research, 35(3), 325-338. doi:10. 2307/3152031.

Lai, V. S., \& Li, H. (2005). Technology acceptance model for internet banking: an invariance analysis. Information Management, 42(2), 373-386. doi:10.1016/j.im.2004.01.007.

Laud, G., Karpen, I. O., Mulye, R., \& Rahman, K. (2015). The role of embeddedness for resource integration: complementing S-D logic research through a social capital perspective. Marketing Theory. doi: 10.1177/1470593115572671.

Lee, J., Park, D.-H., \& Han, I. (2008). The effect of negative online consumer reviews on product attitude: an information processing view. Electronic Commerce Research and Applications, 7(3), 341352. doi:10.1016/j.elerap.2007.05.004.

Levin, D. Z., Cross, R., \& Abrams, L. C. (2002). The strength of weak ties you can trust: the mediating role of trust in effective knowledge transfer. Academy of Management Proceedings, 1-7. Retrieved from http://www.levin.rutgers.edu/research/trust-paper-shortened. pdf.

Lo, S.-K. (2008). The nonverbal communication functions of emoticons in computer-mediated communication. Cyberpsychology \& Behavior, 11(5), 595-597.

Lord, C. G., Ross, L., \& Lepper, M. R. (1979). Biased assimilation and attitude polarization: the effects of prior theories on subseqently considered evidence. Journal of Personality and Social Psychology, 37(11), 2098-2109.

Marketing Science Institute (2010). 2010-2012 MSI Research Priorities. Retrieved from http://www.msi.org/pdf/MSI_RP10-12.pdf.

Mittal, V., Huppertz, J. W., \& Khare, A. (2008). Customer complaining: the role of tie strength and information control. Journal of Retailing, 84(2), 195-204. doi:10.1016/j.jretai. 2008.01.006.

Mizerski, R. W. (1982). An attribution explanation of the disproportionate influence of unfavorable information. Journal of Consumer Research, 9(3), 301. doi:10.1086/208925.

Mudambi, S. M., \& Schuff, D. (2010). What makes a helpful online review? A study of customer reviews on Amazon. com. MIS Quarterly, 34(1), 185-200.

Pan, L.-Y., \& Chiou, J.-S. (2011). How much can you trust online information? Cues for perceived trustworthiness of consumer-generated online information. Journal of Interactive Marketing, 25(2), 67-74. doi:10.1016/j.intmar.2011.01.002.

Park, C., \& Lee, T. M. (2009). Information direction, website reputation and eWOM effect: a moderating role of product type. Journal of Business Research, 62(1), 61-67. doi:10.1016/j.jbusres.2007.11. 017.

Park, J., Baek, Y. M., \& Cha, M. (2014). Cross-cultural comparison of nonverbal cues in emoticons on twitter: evidence from big data analysis. Journal of Communication, 64(2), 333-354. doi:10.1111/ jcom. 12086.

Qiu, L., Pang, J., \& Lim, K. H. (2012). Effects of conflicting aggregated rating on eWOM review credibility and diagnosticity: the moderating role of review valence. Decision Support Systems, 54(1), 631643. doi:10.1016/j.dss.2012.08.020.

Rindfleisch, A., \& Moorman, C. (2001). The acquisition and utilization of information in new product alliances: a strength-of-ties perspective. Journal of Marketing, 65(2), 1-18.
Sawhney, M., Verona, G., \& Prandelli, E. (2005). Collaborating to create: the Internet as a platform for customer engagement in product innovation. Journal of Interactive Marketing, 19(4), 4-17. doi:10.1002/ dir.20046.

Sen, S., \& Lerman, D. (2007). Why are you telling me this? An examination into negative consumer reviews on the Web. Journal of Interactive Marketing, 21(4), 76-94. doi:10.1002/dir.20090.

Skowronski, J. J., \& Carlston, D. E. (1989). Negativity and extremity biases in impression formation: a review of explanations. Psychological Bulletin, 105(1), 131-142. doi:10.1037/0033-2909. 105.1.131.

Steffes, E. M., \& Burgee, L. E. (2009). Social ties and online word of mouth. Internet Research, 19(1), 42-59.

Takac, C., Hinz, O., \& Spann, M. (2011). The social embeddedness of decision making: opportunities and challenges. Electronic Markets, 21(3), 185-195. doi:10.1007/s12525-011-0066-y.

Tsai, W., \& Ghoshal, S. (1998). Social capital and value creation: the role of intrafirm networks. The Academy of Management Journal, 41(4), 464-476. doi:10.2307/257085.

Uzzi, B. (1996). The sources and consequences of embeddedness for the economic performance of organizations: the network effect. American Sociological Review, 61(4), 674-698. doi:10.2307/ 2096399.

van Doorn, J., Lemon, K. N., Mittal, V., Nass, S., Pick, D., Pirner, P., \& Verhoef, P. C. (2010). Customer engagement behavior: theoretical foundations and research directions. Journal of Service Research, 13(3), 253-266. doi:10.1177/1094670510375599.

Vargo, S. L., \& Lusch, R. F. (2004). Evolving to a new dominant logic for marketing. Journal of Marketing, 68(January), 1-17.

Vargo, S. L., \& Lusch, R. F. (2008). Service-dominant logic: continuing the evolution. Journal of the Academy of Marketing Science, 36, 110.

Vivek, S. D., Beatty, S. E., \& Morgan, R. M. (2012). Customer engagement: exploring customer relationships beyond purchase. Journal of Marketing Theory and Practice, 20(2), 127-145.

Wang, J.-C., \& Chang, C.-H. (2013). How online social ties and productrelated risks influence purchase intentions: a Facebook experiment. Electronic Commerce Research and Applications, 12(5), 337-346. doi:10.1016/j.elerap.2013.03.003.

Wang, X., Yu, C., \& Wei, Y. (2012). Social media peer communication and impacts on purchase intentions: a consumer socialization framework. Journal of Interactive Marketing, 26(4), 198-208. doi:10. 1016/j.intmar.2011.11.004.

Wei, W., Miao, L., \& Huang, Z. (2013). Customer engagement behaviors and hotel responses. International Journal of Hospitality Management, 33, 316-330. doi:10.1016/j.ijhm.2012.10.002.

Wen, C., Tan, B. C. Y., \& Chang, K. T.-T. (2009). Advertising effectiveness on social network sites: an investigation of tie strength, endorser expertise and product type on consumer purchase intention. Paper presented at the ICIS 2009 Proceedings. http://aisel.aisnet.org/ icis2009/151.

Willemsen, L. M., Neijens, P. C., Bronner, F., \& de Ridder, J. A. (2011). "Highly recommended!" The content characteristics and perceived usefulness of online consumer reviews. Journal of ComputerMediated Communication, 17(1), 19-38. 